\title{
Midbrain and Lateral Nucleus Accumbens Dopamine Depletion Affects Free-choice High-fat high-sugar Diet Preference in Male Rats
}

\author{
Anil Joshi, ${ }^{a, b, c, d}$ Fanny Faivre, ${ }^{a}$ Susanne Eva la Fleur ${ }^{b, c, d}$ and Michel Barrot ${ }^{a *}$ \\ ${ }^{a}$ Centre National de la Recherche Scientifique, Université de Strasbourg, Institut des Neurosciences Cellulaires et Intégratives, Strasbourg, France \\ ${ }^{\mathrm{b}}$ Amsterdam UMC, University of Amsterdam, Laboratory of Endocrinology, Department of Clinical Chemistry, Amsterdam Gastroenterology \\ \& Metabolism, Amsterdam, the Netherlands \\ ${ }^{c}$ Amsterdam UMC, University of Amsterdam, Department of Endocrinology \& Metabolism, Amsterdam Neuroscience, Amsterdam, the Netherlands \\ ${ }^{\mathrm{d}}$ Metabolism and Reward Group, Netherlands Institute for Neuroscience, An Institute of the Royal Netherlands Academy of Arts and Sciences \\ (KNAW), Amsterdam, the Netherlands
}

\begin{abstract}
Dopamine influences food intake behavior. Reciprocally, food intake, especially of palatable dietary items, can modulate dopamine-related brain circuitries. Among these reciprocal impacts, it has been observed that an increased intake of dietary fat results in blunted dopamine signaling and, to compensate this lowered dopamine function, caloric intake may subsequently increase. To determine how dopamine regulates food preference we performed 6-hydroxydopamine (6-OHDA) lesions, depleting dopamine in specific brain regions in male Sprague Dawley rats. Food preference was assessed by providing the rats with free choice access to control diet, fat, $\mathbf{2 0} \%$ sucrose and tap water. Rats with midbrain lesions targeting the substantia nigra (which is also a model of Parkinson's disease) consumed fewer calories, as reflected by a decrease in control diet intake, but they surprisingly displayed an increase in fat intake, without change in the sucrose solution intake compared to sham animals. To determine which of the midbrain dopamine projections may contribute to this effect, we next compared the impact of 6-OHDA lesions of terminal fields, targeting the dorsal striatum, the lateral nucleus accumbens and the medial nucleus accumbens. We found that 6-OHDA lesion of the lateral nucleus accumbens, but not of the dorsal striatum or the medial nucleus accumbens, led to increased fat intake. These findings indicate a role for lateral nucleus accumbens dopamine in regulating food preference, in particular the intake of fat. $($ ) 2021 IBRO. Published by Elsevier Ltd. All rights reserved.
\end{abstract}

Key words: substantia nigra, 6-OHDA, lateral nucleus accumbens, fcHFHS, diet preference, fat.

\section{INTRODUCTION}

Food intake is a highly reinforced behavior that not only provides nutrients needed for survival, but that also induces feelings of joy and pleasure (Hoebel, 1985). Modern human diet and natural rewards include a substantial amount of sugars and fats, which can modulate dopamine signaling in the brain reward system (DiFeliceantonio et al., 2018; Fritz et al., 2018; Fernandes et al., 2020) and could disturb the internal homeostatic mechanism which regulates hunger and satiety, ultimately contributing to food over-consumption and obesity (de Araujo

\footnotetext{
${ }^{*}$ Corresponding author.

E-mail address: mbarrot@inci-cnrs.unistra.fr (M. Barrot).

Abbreviations: 6-OHDA, 6-hydroxydopamine; ANOVA, analysis of variance; $\mathrm{AP}$, anteroposterior; $\mathrm{DA}$, dopamine; DLS, dorsolateral striatum; fcHFHS, free-choice high-fat high-sugar; L, lateral; INAc, lateral nucleus accumbens; mNAc, medial nucleus accumbens; PB, phosphate buffer; PBS, phosphate buffer saline; PBS-T, PBS with Triton X-100; SNc, substantia nigra pars compacta; $\mathrm{TH}$, tyrosine hydroxylase; V, vertical; VTA, ventral tegmental area
}

et al., 2008; Han et al., 2018; Zimmerman and Knight, 2020).

Homeostatic signals that influence the excitability of midbrain dopamine neurons can influence the sensitivity to drugs (Volkow et al., 2017) and it is an ongoing debate whether over-consumption of palatable food and drug addiction do share a similar mechanism (Fletcher and Kenny, 2018). Dopamine is one of the important neurotransmitters involved in reward processing, including in the rewarding aspects of food intake (Hernandez and Hoebel, 1988; Berke, 2018; Cox and Witten, 2019). The midbrain dopamine neurons of the substantia nigra pars compacta (SNc) and of the ventral tegmental area (VTA) are the main sources of dopamine projections to the forebrain striatal complex (Gerfen and Bolam, 2016), which in rodents includes the dorsal striatum that is analogous to the caudate and putamen nuclei in primates and humans (Haber, 2016), and the ventral striatum that includes the nucleus accumbens and the olfactory tubercle. The nucleus accumbens, which has been proposed 
as an interface from motivation to action (Mogenson et al., 1980), is itself heterogeneous (Castro and Bruchas, 2019; Park et al., 2019), with two main subregions, the core and the shell (Záborszky et al., 1985; Zahm, 1999), as well as mediolateral and/or anteroposterior anatomical and functional heterogeneity. Classically, the VTA dopamine neurons that project to the ventral striatum have been linked to reward processes (Lammel et al., 2012; Hamid et al., 2016; Hu, 2016; Morales and Margolis, 2017), whereas $\mathrm{SNc}$ dopamine neurons that project to the dorsal striatum are more often associated with motor control (Howe and Dombeck, 2016; da Silva et al., 2018). However, this dichotomy has been challenged and several studies have shown that SNc neurons projecting to the dorsal striatum can also be linked to food-motivation (llango et al., 2014; London et al., 2018; Lee et al., 2020) and associated movements (Lee et al., 2020). Little is known however about SNc striatal projections in relation to obesogenic diets. Dopamine deficient mice lack goal-directed feeding behavior and die of starvation by the age of 4 weeks (Palmiter, 2008); however, if the dopamine signaling is restored in the striatum (Szczypka et al., 2001) or in the dopamine neurons that project to the dorsal striatum (Sotak et al., 2005; Hnasko et al., 2006), then these mice consume enough for survival. Similarly, feeding inhibition is seen when dopamine signaling is altered in the dorsal striatum (Sotak et al., 2005).

As observed for drugs of abuse, palatable food can elicit altered dopaminergic signaling in the striatum. It has, for example, been shown that intragastrical fat infusions increase extracellular dopamine levels in the dorsal striatum (Ferreira et al., 2012). Dopamine signaling is also altered in the nucleus accumbens during the consumption of diets that are rich in fat and/or sugar (Hajnal et al., 2004; Liang et al., 2006; Rada et al., 2012) or during food restriction (Carr, 2020). An excessive consumption of fats has been shown to reduce brain dopaminergic function, and it has been hypothesized that this dopamine deficiency may aggravate obesity by favoring overfeeding as a compensatory mechanism to restore reward sensitivity (Tellez et al., 2013). A palatable high-fat diet has thus been proposed to promote addictive-like behavior in rats by downregulating $D_{2}$ receptors while promoting obesity (Johnson and Kenny, 2010), which is in agreement with human positron emission tomography (PET) scanning in obese subjects showing lower availability of $D_{2}$ receptor in the striatum (Wang et al., 2001; de Weijer et al., 2011). It is however to be noted that the hypothesis of dopamine deficiency in obesity is controversial as other publications did not support it (Eisenstein et al., 2013; Gaiser et al., 2016), or even suggested that changes in $D_{2}$ receptor availability may relate to age rather than to body mass index (Dang et al., 2016). In rodents, it has been shown that rats under a free-choice high-fat highsugar (fcHFHS) paradigm have decreased striatal $D_{2}$ receptor availability (van de Giessen et al., 2013), and that male rats fed with a diet rich in saturated dietary lipids (palm oil) have reduced $D_{1}$-mediated signaling in the nucleus accumbens (Hryhorczuk et al., 2016). Systemic manipulation of dopamine transmission using uptake inhibitors (van de Giessen et al., 2012; Randall et al., 2014) or receptor agonist/antagonists (Rolls et al., 1974; Gilbert and Cooper, 1985; Clifton et al., 1991; Terry and Katz, 1992; Baker et al., 2001) can decrease food intake. More localized optogenetic stimulation of the nucleus accumbens medium spiny neurons expressing the $D_{1}$ receptors (or of their terminals in the lateral hypothalamus) decreased feeding in mice, while the inhibition of these neurons favored it (O'Connor et al., 2015); and chemogenetic activation of these neurons also decreased food intake (Luo et al., 2018). However, the influence that dopamine projections may exert on the preference between different types of food remains to be detailed.

Parkinson's disease is a neurodegenerative disorder associated with a loss of dopamine neurons in the midbrain. This loss preferentially concerns dopamine neurons of the SNc (Bezard and Przedborski, 2011; Zimmerman and Knight, 2020), which are more sensitive to cell death than VTA ones. Interestingly, some studies suggested that food preference may be altered in Parkinson's disease patients. Indeed, increased preference for palatable food, such as chocolate (Hellenbrand et al., 1996; Wolz et al., 2009), ice-cream (Meyers et al., 2010), cakes, buns, milk (Lorefält et al., 2006) and carbohydrate (Ådén et al., 2011), have been reported, with a decrease in consumption of fresh fruits, vegetables (Hellenbrand et al., 1996; Lorefält et al., 2006) and protein (Ådén et al., 2011). In rodents, models of Parkinson's disease have not been studied yet for potential changes in food choice.

In the present study, we used 6-hydroxydopamine (6OHDA) lesions of midbrain SNc dopamine neurons, a model of Parkinson's disease (Faivre et al., 2019), to study the influence of this dopamine cell loss in the fcHFHS paradigm, an obesogenic diet known to facilitate obesity and insulin resistance (la Fleur et al., 2010, 2011). Besides the known decrease in global food and calorie intake, the results revealed a surprising increase in fat intake following 6-OHDA SNc lesion. To understand which dopamine projection may underlie this impact on fat intake, we then lesioned terminals of specific dopamine projections within the striatal complex. This study, conducted in the rat, highlights a role for dopamine in the lateral nucleus accumbens in fat choice and intake.

\section{EXPERIMENTAL PROCEDURES}

\section{Animals}

Adult male Sprague-Dawley rats (Janvier Labs, France) were housed under standard conditions (2 per cage, $22 \pm 1{ }^{\circ} \mathrm{C}, 12$-h light-dark cycle) and habituated to the animal facility for at least a week before starting procedures. A total of 128 rats were purchased for the various experiments and, out of these, 118 rats were finally used for food intake behavior. Animal care and use were performed in accordance with the Centre National de la Recherche Scientifique (CNRS) and the European Union directives, with procedures approved by the regional ethical committee (CREMEAS). 


\section{Surgical procedures}

Rats (7-8 weeks old; $250-325 \mathrm{~g}$ ) were anesthetized using either ketamine (Imalgene ${ }^{\circledR}$ 1000)/xylazine (Rompun $\AA$ $2 \%) /$ acepromazine (Calmivet $\left.{ }^{\circledR}\right)(80 \mathrm{mg} / \mathrm{kg}, 4 \mathrm{mg} / \mathrm{kg}$ and $1 \mathrm{mg} / \mathrm{mL}$ respectively; intraperitoneal (i.p.)) or using zolazepam (Zoletil $\circledast 50) /$ xylazine (Rompun $\circledast)$ ) $(65 \mathrm{mg} / \mathrm{kg}$ and $14 \mathrm{mg} / \mathrm{kg}$ respectively; i.p.), and placed in a stereotaxic frame (Kopf Instruments). Ocry-gel ${ }^{\circledR}$ was used to protect the eyes; and subcutaneous bupivacaine $(40 \mu \mathrm{L} / 100 \mathrm{~g})$ and Metacam ${ }^{\circledR}(50 \mu \mathrm{L} / 100 \mathrm{~g})$ were used as local anesthetic for surgery and as antiinflammatory drug for postsurgical pain relief respectively. Stereotaxic coordinates relative to the bregma were adjusted to the animal weight based on trial animals with blue dye injections. Coordinates (in $\mathrm{mm}$ ) were as follows (Paxinos and Watson, 2013): SNc, anteroposterior $(\mathrm{AP})=-5.1$, lateral $(\mathrm{L})= \pm 2.2$, vertical $(\mathrm{V})=-7.4$; dorsolateral striatum, $\mathrm{AP}=+1.7, L= \pm 3.1$, $V=-4.2$; medial nucleus accumbens (mNAc), $\mathrm{AP}=+1.8, L=+1.5, V=-6.9$; and lateral nucleus accumbens (INAC), AP $=1.5, L= \pm 2.6, V=-7.0$. Verticality was taken from the dura. Hamilton syringes with 33 gauge needles were used to deliver $2 \mu \mathrm{L}$ of 6-OHDA (Sigma-Aldrich, France; $2.5 \mu \mathrm{g} / \mu \mathrm{L}$ in $0.9 \% \mathrm{NaCl}$ with $0.01 \%$ ascorbic acid) (Faivre et al., 2020) bilaterally, over $4 \mathrm{~min}$. Needles were removed $7 \mathrm{~min}$ after the end of the injection. The sham surgeries were performed in a similar way, without injection. Rats were allowed to recover for 3 weeks before starting the behavioral experiments.

\section{fcHFHS experiments}

The fcHFHS paradigm (la Fleur et al., 2014) was implemented to assess food/fluid choice and intake following $6-O H D A$ lesions. This fcHFHS feeding setup provides rodents an easy access to choose from several food components which are varying in palatability, fluidity, texture, form, and nutritive content (Slomp et al., 2019). The test was performed over 7 days. Rats were single housed in Type 4 cages, and given free access to normal chow (diet A04, SAFE, France), fat (Les Pâturages des Flandres pure graisse de bœuf, Sarl Buchez, estaires, France), $20 \%$ sucrose solution (Sigma-Aldrich), and water. The two bottles were placed on each side of the stainless steel lid recess, and the two types of food were placed in between with separators. On each day, the position of the water and sucrose bottles was interchanged, with a change in fat and chow positions every other day. The SNc lesion experiment initially included 25 sham and 27 lesioned rats (done over three independent batches of animals to confirm the findings), the dorsolateral striatum lesion experiment eight sham and eight lesioned rats, the mNAc lesion experiment 10 sham and 14 lesioned rats, the INAc lesion experiment 12 sham and 14 lesioned rats.

\section{Immunohistochemistry}

After completion of behavioral testing, rats were killed with a sodium pentobarbital overdose $(235 \mathrm{mg} / \mathrm{kg}$, i.p.) and decapitated. Their brains were collected and fixed in a paraformaldehyde solution ( $4 \%$ in $0.1 \mathrm{M}$ phosphate buffer (PB), pH 7.4) with $20 \%$ glycerol for $24 \mathrm{~h}$, and transferred to a $20 \%$ sucrose solution in PB for further cryoprotection. Coronal sections $(40 \mu \mathrm{m})$ were cut using a cryotome (Leica SM 2000R). Immunohistochemistry against tyrosine hydroxylase (TH) was performed as previously described (Faivre et al., 2020). At room temperature, free-floating sections were washed 3 times with $0.9 \% \mathrm{NaCl} / 0.01 \mathrm{M} \mathrm{PB} \mathrm{pH} 7.4$ (PBS), incubated in 50\% ethanol with $0.03 \%$ hydrogen peroxide for $30 \mathrm{~min}$ for endoperoxidase blocking, washed 3 times with PBS, incubated in $0.3 \%$ Triton X-100 in PBS (PBS-T) with $5 \%$ normal donkey serum for permeabilization and blocking for $45 \mathrm{~min}$, and incubated overnight with the anti-TH primary antibodies (Millipore-Chemicon MAB318, 1/5000 for SNc sections and $1 / 2000$ for striatal/NAc sections) in PBS-T with $1 \%$ normal donkey serum. On the following day, sections were washed 3 times with PBS, incubated with an anti-lgG biotinylated secondary antibody (\#BA2001, Vector Laboratories 1/200) in PBS for 90 min, washed 3 times with PBS, and incubated with the avidin-biotin-peroxi dase complex (ABC Elite; Vector Laboratories). The amplified complex was finally revealed with a peroxidase/3.3'-diaminobenzidine tetrahydrochloride reaction. The sections were mounted, dried with a gradient of alcohol followed by Roti®-Histol solution, and a glass coverslip was placed using Eukitt ${ }^{\circledR}$.

\section{Microscopy and analysis}

The mounted slides were scanned in a NanoZoomer S60 Digital slide scanner C13210 (Hamamatsu) at 20x in bright field. Images were saved in Nanozoomer Digital Pathology Image (ndpi) format and the uncompressed images were viewed in NDP.view 2.6.13 and extracted in .tif format for analyses using Image $\mathrm{J}$. The images were converted into greyscale and the grey densities were calculated on 5-6 sections per animal and per region. Striatum and NAc data were expressed as optical density, and SNc/VTA data were expressed as $\%$ of the mean integrated grey density in controls. Sections ranging from AP +2.2 to +1.2 from bregma were selected for analyses of the striatum and NAc, while sections ranging from AP -4.6 to -5.8 were used for SNc and VTA analyses.

\section{Statistics}

Results are expressed as mean \pm SEM in figures. Statistical analyses were performed using STATISTICA 13 software (Statsoft, Tulsa, OK, USA) and GraphPad Prism 8.04 (GraphPad Software, La Jolla California USA). We used parametric statistical tests after controlling for normal distributions of data using the Kolmogorov-Smirnov test and for equal variances in sampled distributions using the Levene's test. Student's t-test was used for two group comparison for lesion extent and for total kcal intake. ANOVA was used for comparing different food/fluid intakes over days (within factors) between the sham and lesion groups (between factor), followed by Duncan post hoc, with the level of significance at $p<0.05$. 


\section{RESULTS}

\section{Effects of substantia nigra lesion on high-fat high- sugar free choice feeding}

The SNc was lesioned using 6-OHDA and the extent of the lesions at cell body and terminal levels was controlled by $\mathrm{TH}$ immunohistochemistry at the end of the experiments (Fig. 1A-D). Lesioned animals were considered for the analysis of behavioral data if they bilaterally displayed at least a $50 \%$ loss in SNc TH staining (Fig. 1C, E), which concerned 22 out of the 27 rats that received 6-OHDA. In those animals, the lesions concerned the $\mathrm{SNc}$, but could also extend to the lateral parts of the VTA (Fig. 1E). The impact on TH density in the striatal and nucleus accumbens terminal field was also controlled for (Fig. 1D, F).

The fcHFHS paradigm was conducted over 7 days. Overall, the SNc lesion led to a decrease in total kcal intake per $100 \mathrm{~g}$ body weight $\left(\mathrm{F}_{1,45}=4.41, p=0.04\right)$ (Fig. 2A, C). With time, the rats also displayed slightly lower body weight than control $\left(F_{4,200}=7.29\right.$, $p<0.0001$ ) (Supplementary Fig. 1SA). Interestingly, the decrease in kcal intake was associated with a change in the nutrient choice $\left(\mathrm{F}_{2,90}=8.23\right.$, $p=0.0004)$ : the rats decreased their chow intake (post-hoc, $p=0.00002$ ), increased their fat intake $(p=0.01)$, and maintained their sugar intake $(p=0.44)$. As total intake differed between lesioned animals and their controls, we also standardized the data (\% of intake for each animal) (Fig. 2B), which confirmed the increased intake of high-fat food to the detriment of regular chow $\left(\mathrm{F}_{2,90}=4.88, p=0.009\right.$; post hoc: decreased chow $p=0.006$, increased highfat $p=0.006$, unchanged sucrose $p=0.99$ ). This difference appeared as robust as it was stable over days $\left(F_{12,540}=1.42, p=0.15\right)$.

When looking more closely at the individual pattern of nutrient choice (Fig. 2D; Supplementary Fig. S2A), a highly stable pattern was observed among the 25 animals of the Sham group. This pattern of choice was however strongly disrupted in some of the 6-OHDA lesioned animals. In particular, the mean increase in high-fat food intake was in fact due to 6 animals only (27\% of the cohort), and those animals were among the ones with the largest extent of striatal loss in $\mathrm{TH}$ staining (blue animal numbers in Fig. 1; blue lines in Fig. 2D and in Supplementary Fig. S2A). This observation led us to study more closely the role of dopamine terminals from different striatal subregions in the fcHFHS paradigm and high-fat food intake.

\section{Effects of dopamine depletion in the dorsolateral striatum on high-fat high-sugar free choice feeding}

We first tested the influence of dopamine terminals in the dorsolateral striatum, by performing local 6-OHDA injections (Fig. $3 \mathrm{~A}-\mathrm{C}$ ). TH staining was used to control the extent of these lesions, which were limited to the lateral and dorsolateral parts of the dorsal striatum (Fig. $3 \mathrm{C}$ ). With the fcHFHS paradigm, we observed no impact of the lesions on the total kcal intake per $100 \mathrm{~g}$ body weight $\left(\mathrm{F}_{1,14}=0.05, p=0.81\right)$ (Fig. 3D, $\left.\mathrm{F}\right)$, or on the choice between regular chow, high-fat diet and sucrose solution $\left(F_{2,28}=1.38, p=0.26\right)$ (Fig. $\left.3 E\right)$. The individual patterns of nutrient choice (Fig. 3G; Supplementary Fig. S2B) further supported this lack of impact of the dorsolateral striatum lesions, except for one animal with higher fat intake (blue line in Fig. 3G and in Supplementary Fig. S2B) that displayed a ventrolateral extent of the lesion (picture insert in Fig. 3G). We then lesioned the dopamine terminals in the INAc to test their influence on the fcHFHS paradigm and high-fat food intake.

\section{Effects of dopamine depletion in the nucleus accumbens on high-fat high-sugar free choice feeding}

The 6-OHDA lesion of the INAc (Fig. 4A-C) led to an overall increase in total kcal intake per $100 \mathrm{~g}$ body weight $\left(F_{1,24}=11.53, p=0.002\right)$ (Fig. $\left.4 \mathrm{D}, F\right)$. This increase was more specifically due to a change in the nutrient choice $\left(F_{2,48}=6.92, p=0.002\right)$, with an increased intake of high-fat food (post hoc, $p=0.00006)$ and no quantitative change in chow $(p=0.72)$ and sucrose $(p=0.64)$ intake. When data were standardized (\% of intake for each animal) (Fig. 4E), it confirmed the increased choice of high-fat food, mostly to the detriment of regular chow $\left(F_{2,48}=7.80, p=0.001\right.$; post hoc: decreased chow $p=0.01$, increased high-fat $p=0.0003$, unchanged sucrose $p=0.18$ ). The individual patterns of nutrient choice (Fig. 4G; Supplementary Fig. S2C) further supported the overall increase in high-fat food intake.

We then tested whether this role could be extended to the rest of the NAc or was specific to the INAc subregion. In the fcHFHS paradigm, the 6-OHDA lesion of the mNAc (Fig. 5A-C) had no significant impact on the total kcal intake per $100 \mathrm{~g}$ body weight $\left(\mathrm{F}_{1,22}=0.002, p=0.96\right)$ (Fig. 5D, F), or on the choice between regular chow, high-fat diet and sucrose solution (intake: $F_{2,44}=0.50$, $p=0.60 ; \%: F_{2,44}=0.44, p=0.64$ ) (Fig. 5D-G; and in Supplementary Fig. S2D), which supported a specific influence of the INAc on high-fat choice.

\section{DISCUSSION}

In the present study, we used a fcHFHS diet preference paradigm in rats in order to identify the impact of dopamine loss on food intake and preference. Our results highlighted a role of dopamine terminals in the lateral nucleus accumbens in the regulation of fat intake.

6-OHDA is a neurotoxin widely used to model Parkinson's disease (Faivre et al., 2019) and to study reduced dopamine states. This toxin enters the dopamine and noradrenaline neurons and terminals through the dopamine transporter and the noradrenaline transporter, and it produces reactive oxygen species thus causing the death of the catecholaminergic neurons and/or their terminals (Ungerstedt, 1968). The nigrostriatal dopamine system is important for feeding behavior as complete bilateral degeneration of SNc with 6-OHDA causes adipsia and aphagia (Ungerstedt, 1971). Similarly, dopamine 
A Sham

C

SNC/NTA

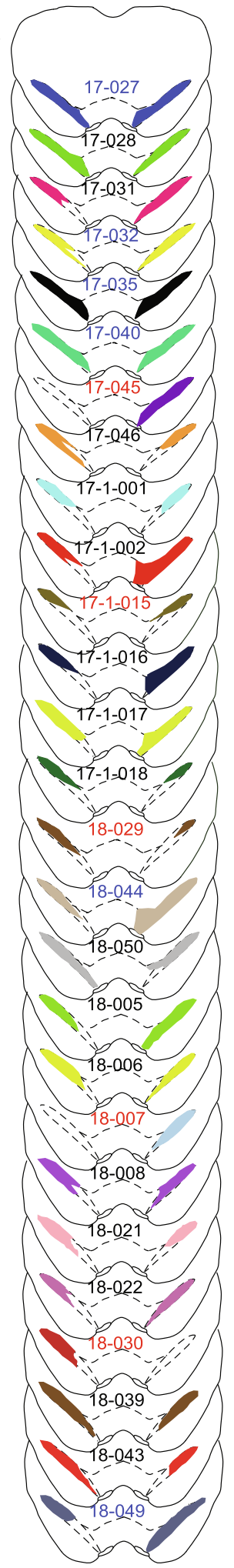

TH Sham

TH

B 6-OHDA
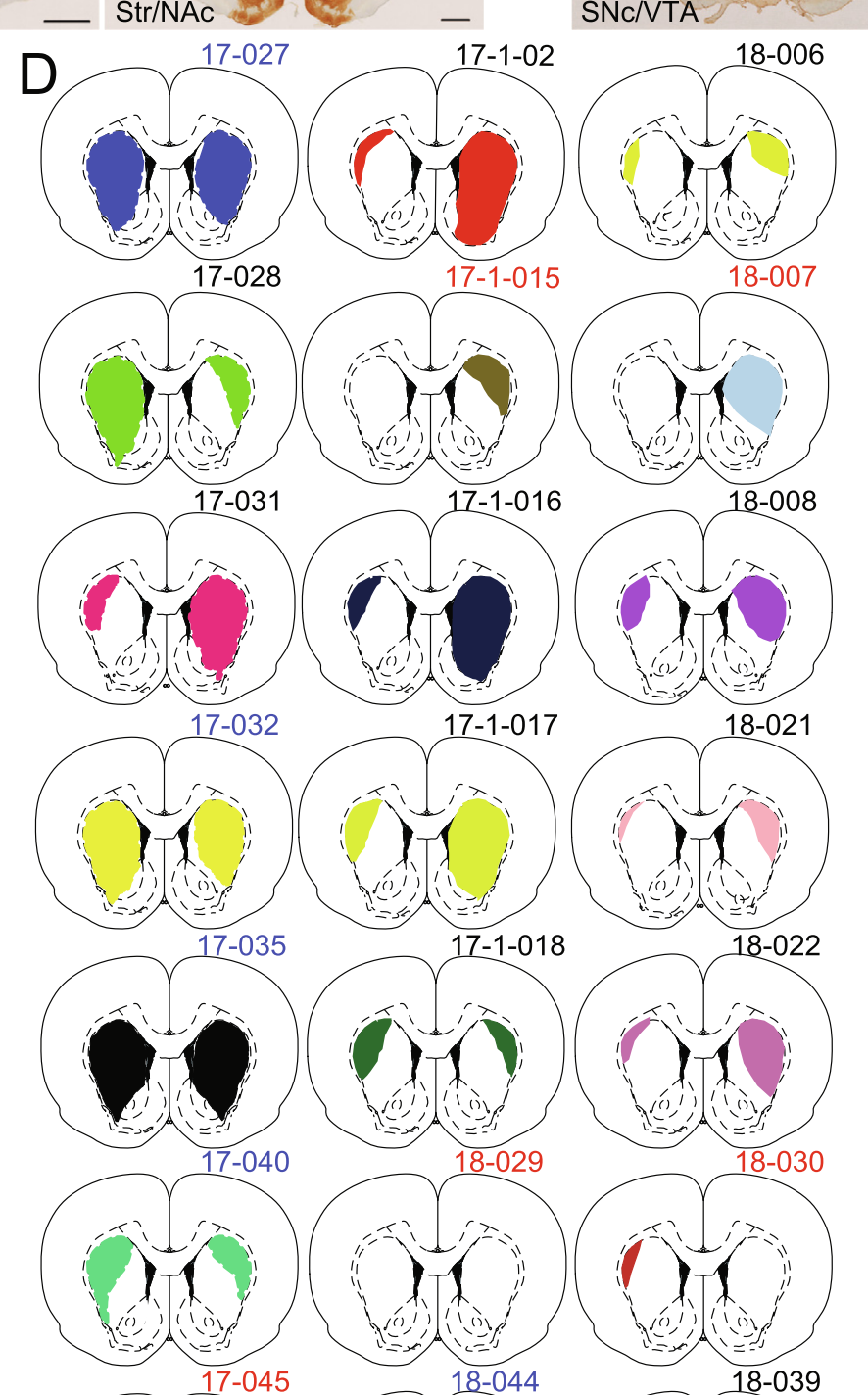

TH 6-OHDA

TH 


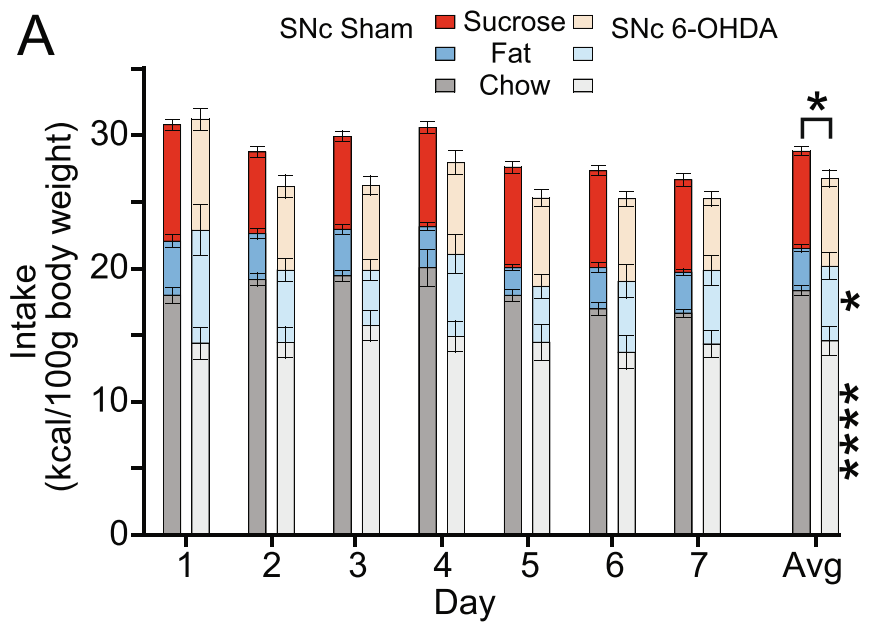

B
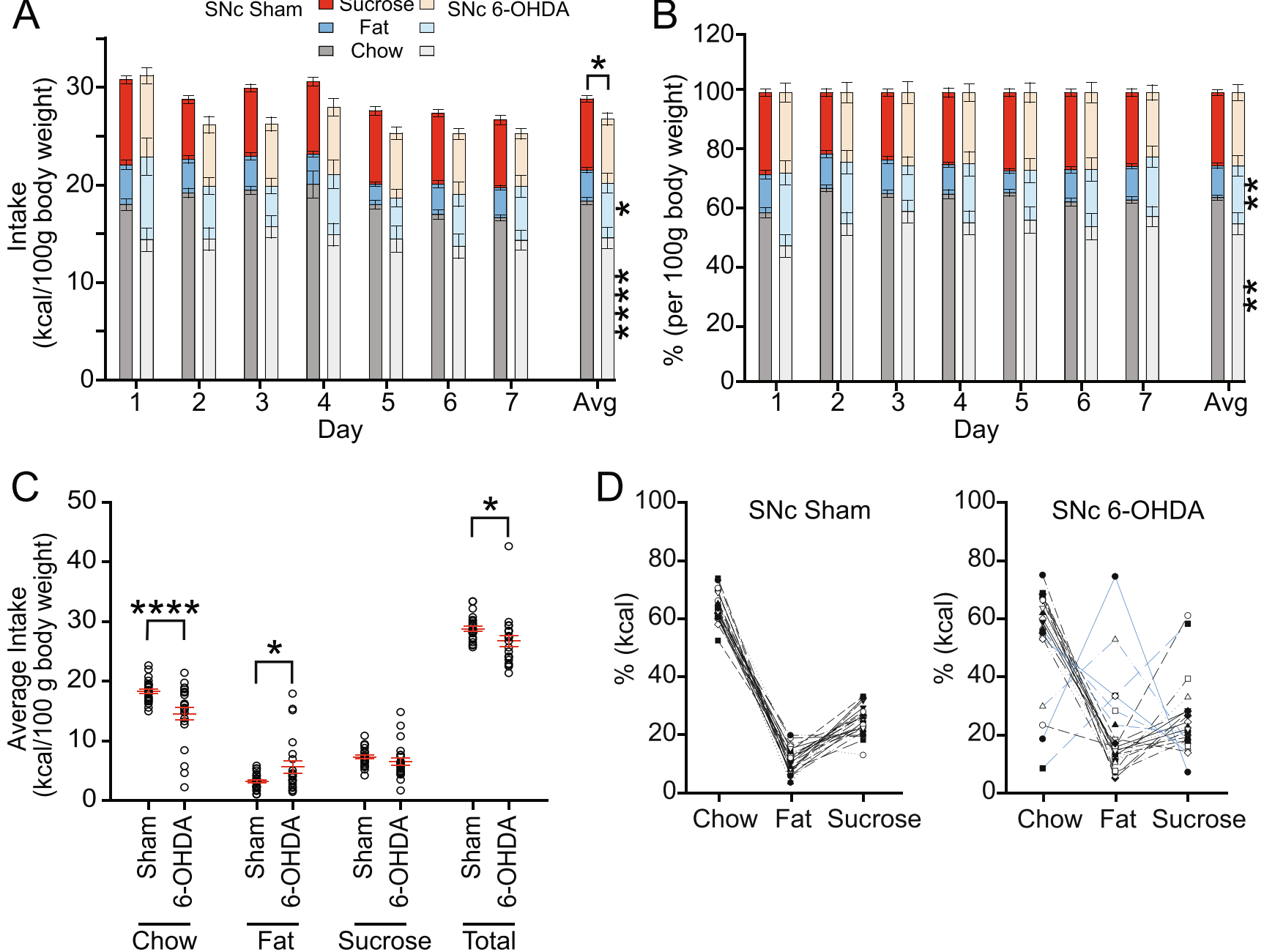

Fig. 2. High-fat High-sugar free choice in SNc lesioned animals. Daily nutrient intake pattern in sham $(n=25)$ and 6-OHDA animals $(n=22)$ for the three nutrient types over 7 days, in kcal per 100 gram of body weight (A), and in percentage of kcal consumed from different nutrient types (B). (C) Individual average $\mathrm{kcal}$ intake per $100 \mathrm{~g}$ of body weight in sham and 6-OHDA animals. (D) Individual patterns of nutrient choice (\% of kcal intake) in sham and 6-OHDA animals. The blue lines identify the animals with the largest extent of striatal loss in TH staining. Data are presented as mean \pm SEM. ${ }^{*} p<0.05 ;{ }^{* *} p<0.01 ;{ }^{* \star *} p<0.001 ;{ }^{* \star *} p<0.0001$. 6-OHDA, 6-hydroxydopamine; Avg, average; SNc, substantia nigra pars compacta.

deficient mice are hypoactive and aphagic, leading to starvation and death if they are not given L-Dopa (Palmiter, 2008). However, an appropriate postoperative care allows animals with partial bilateral SNc lesion to consume sufficient food and prevents animal loss (Faivre et al., 2020). In the present study, tests were performed after such postoperative care and 3 weeks of post-surgical recovery, with regular monitoring of bodyweight. It allowed ensuring that SNc lesioned animals were in capacity to eat, drink and gain weight, even though a slowdown of weight intake was present (Supplementary Fig. S1A).

As previously observed (Faivre et al., 2020), the animals with bilateral SNc lesion displayed lower body weight gain. This decreased weight gain may likely be due to the lower kcal intake from standard chow in comparison with sham animals. This reduced weight gain was however only observed with midbrain SNc lesions, but was not present with more selective terminal lesions. Decreased weight gain or even weight loss is not limited

Fig. 1. Midbrain 6-OHDA lesions. Examples of tyrosine hydroxylase (TH) immunostaining in the SNc/VTA area and in the Str/NAc area for sham $(n=25)(\mathbf{A})$ and for 6-OHDA $(n=27)(\mathbf{B})$ injected rats (scale bars, $1 \mathrm{~mm})$. Individual extent of the lesion: the colored area corresponds to the lesioned area at the site of injection (C) and at Str/NAc projection level (D) after 6-OHDA injection. The experimental identity number of each rat is displayed nearby drawings; the red color identifies animals with less than $50 \%$ of bilateral TH immunostaining loss in the SNc that were removed from behavioral analyses and the blue color identifies animals with the largest extent of striatal loss in TH staining. (E) Graph representing the integrated grey density (I.G.D.) of TH immunostaining in the SNc and VTA. (F) Optical density (O.D.) of TH immunostaining in different subregions of the Str/NAc. 6-OHDA, 6-hydroxydopamine; NAc, nucleus accumbens; SNc, substantia nigra pars compacta; Str, striatum; VTA, ventral tegmental area. 

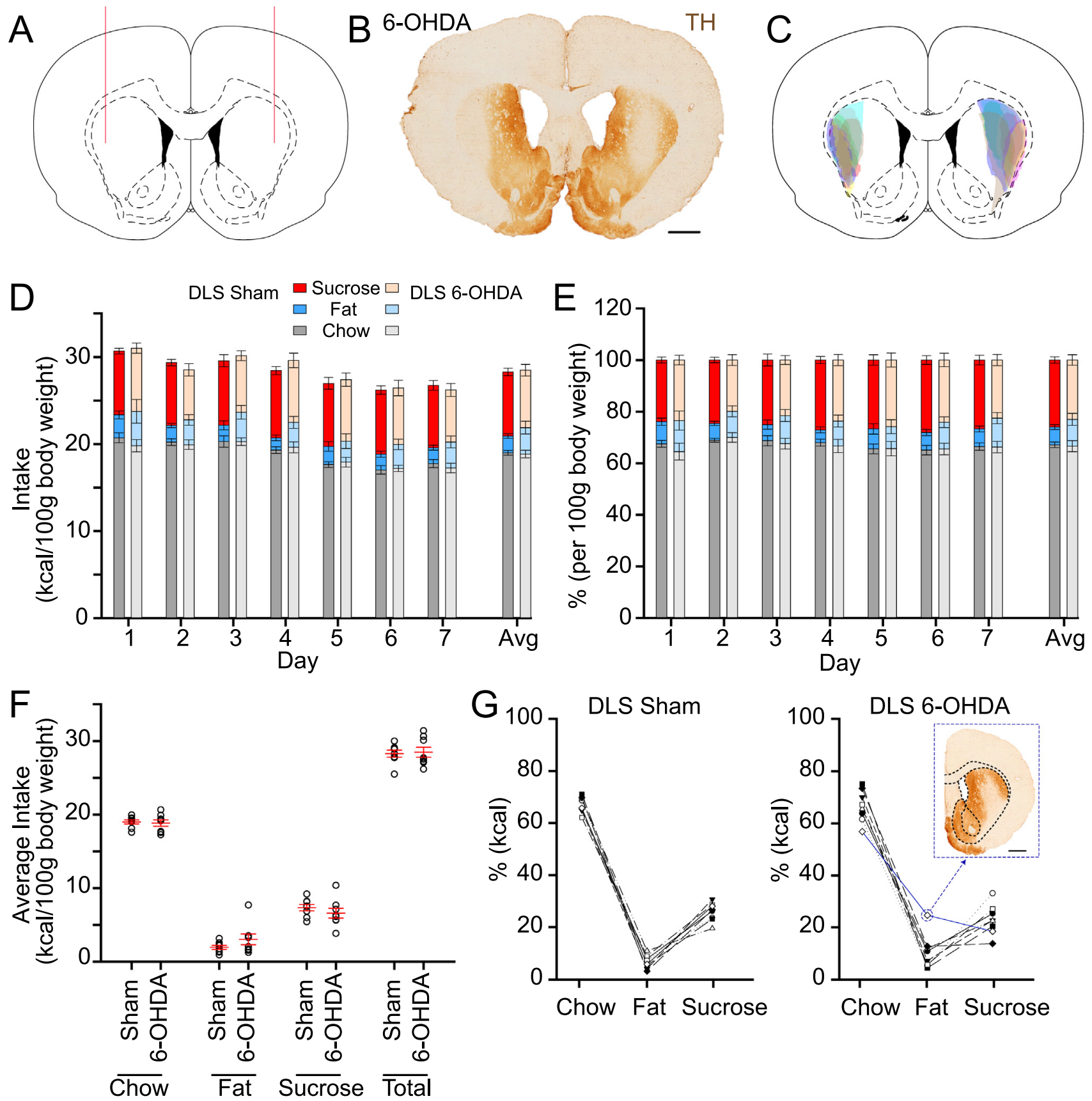

Fig. 3. High-fat High-sugar free choice in DLS lesioned animals. Schematic of injection site (A), example of tyrosine hydroxylase immunostaining (B) and schematic reconstruction of individual lesion extents (C). Daily nutrient intake pattern in sham $(n=8)$ and 6-OHDA animals $(n=8)$ for the three nutrient types over 7 days, in kcal per 100 gram of body weight (D), and in percentage of kcal consumed from different nutrient types (E). (F) Individual average kcal intake per $100 \mathrm{~g}$ of body weight in sham and 6-OHDA animals. (G) Individual patterns of nutrient choice (\% of kcal intake) in sham and 6-OHDA animals. The picture insert displays TH immunostaining in the animal with high fat intake (blue line). Data are presented as mean \pm SEM. Scale bars, $1 \mathrm{~mm}$. 6-OHDA, 6-hydroxydopamine; Avg, average; DLS, dorsolateral striatum.

to the 6-OHDA model of Parkinson's disease. Indeed, weight loss is also present with aging in the MitoPark transgenic mouse model ( $\mathrm{Li}$ et al., 2013). Besides, mice expressing the A53T human alpha-synuclein mutation (Giasson et al., 2002), the Thy1-aSYN Mice (Cuvelier et al., 2018), and the PINK1 deficient mice (Gispert et al., 2009), also display reduced body weight gain over time. Similarly, in the MPTP (1-methyl-4-phenyl-1,2,3,6-t etrahydropyridine) model of Parkinson's disease in the primate, a daily care of the animals is essential otherwise animals may die due to adipsia, aphagia and loss of body weight (Porras et al., 2012). However, it is to be noted that MPTP-treated mice (Sundstrom et al., 1990; MunozManchado et al., 2016; Zhang et al., 2017) and the LRRK2 G2019S transgenic mice (Bieri et al., 2019) may not display noticeable change in body weight. Clinically, Parkinson's disease patients are known to have weight fluctuations. Weight loss has been reported in early as 

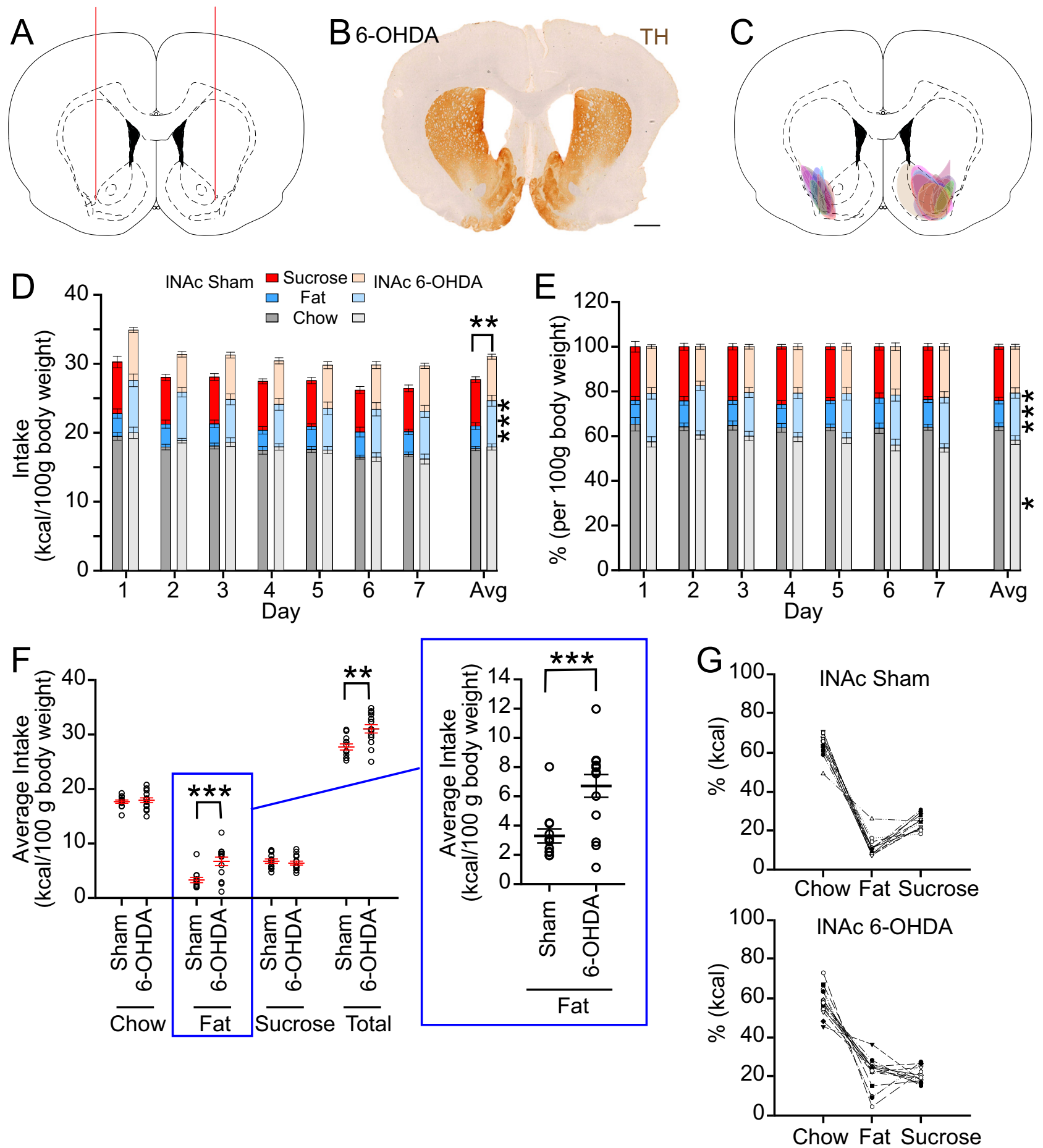

Fig. 4. High-fat High-sugar free choice in lateral NAc lesioned animals. Schematic of injection site (A), example of tyrosine hydroxylase immunostaining (B) and schematic reconstruction of individual lesion extents (C). Daily nutrient intake pattern in sham $(n=12)$ and 6-OHDA animals $(n=14)$ for the three nutrient types over 7 days, in kcal per 100 gram of body weight (D), and in percentage of kcal consumed from different nutrient types (E). (F) Individual average kcal intake per $100 \mathrm{~g}$ of body weight in sham and 6-OHDA animals, the insert details the individual fat intake. (G) Individual patterns of nutrient choice (\% of kcal intake) in sham and 6-OHDA animals. Data are presented as mean \pm SEM. ${ }^{*} p<0.05$; ${ }^{* *} p<0.01 ;{ }^{* * *} p<0.001$. Scale bar, $1 \mathrm{~mm}$. 6-OHDA, 6-hydroxydopamine; Avg, average; INAc, lateral nucleus accumbens.

well as advanced forms of the Parkinson's disease (Kistner et al., 2014; Ma et al., 2018), whereas some patients may show again increased weight gain with dopamine replacement therapy, pallidotomy or subthalamic nucleus deep brain stimulation (Kistner et al., 2014;
Ma et al., 2018). Beside weight fluctuations, it has been proposed that Parkinson's disease patients may also display alterations in food preference (Aiello et al., 2015), with an increased preference for palatable food rich in fat and sugar (Hellenbrand et al., 1996; Wolz et al., 

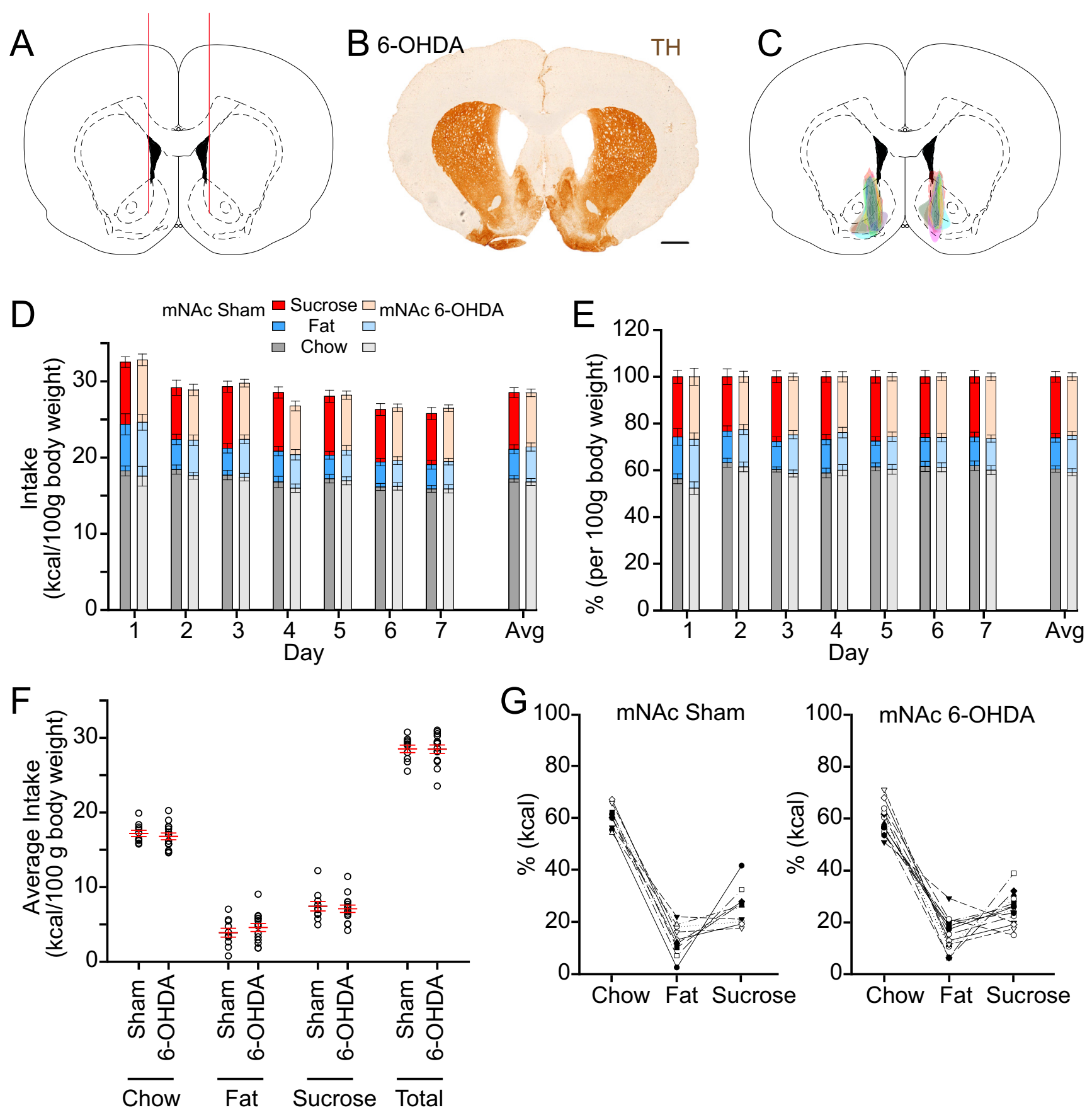

Fig. 5. High-fat High-sugar free choice in medial NAc lesioned animals. Schematic of injection site (A), example of tyrosine hydroxylase immunostaining (B) and schematic reconstruction of individual lesion extents (C). Daily nutrient intake pattern in sham ( $n=10)$ and 6-OHDA animals $(n=14)$ for the three nutrient types over 7 days, in kcal per 100 gram of body weight (D), and in percentage of kcal consumed from different nutrient types (E). (F) Individual average kcal intake per $100 \mathrm{~g}$ of body weight in sham and 6-OHDA animals. (G) Individual patterns of nutrient choice (\% of kcal intake) in sham and 6-OHDA animals. Data are presented as mean \pm SEM. Scale bar, $1 \mathrm{~mm}$. 6-OHDA, 6-hydroxydopamine; Avg, average; mNAc, medial nucleus accumbens.

2009; Meyers et al., 2010), to the detriment of fresh fruits, vegetables and protein (Hellenbrand et al., 1996; Lorefält et al., 2006; Ådén et al., 2011). In the animals, food choice paradigms were however not yet applied to the 6-OHDA $\mathrm{SNc}$ lesion model of Parkinson's disease. The use of the fcHFHS paradigm allowed us to observe that, beside the expected decreased in kcal intake, SNc lesioned animals did not display notable change in sucrose consumption but had a perturbed food intake pattern, with about a third of the animals surprisingly displaying an increased kcal consumption from the fat source. This heterogeneity in individual data suggested that the subpopulation of lesioned dopamine neurons may be of importance and could explain interindividual variability in 
the consequences of the lesion. We thus targeted different dopamine terminal fields to test their influence on the fcHFHS paradigm.

The pharmacological or viral-mediated rescue of dopamine system in the dorsal striatum has been shown to restore feeding behavior in dopamine (tyrosine hydroxylase) deficient mice (Zhou and Palmiter, 1995; Szczypka et al., 2001; Sotak et al., 2005; Hnasko et al., 2006; Palmiter, 2008). These mice could indeed consume sufficient food for survival when a recombinant adenoassociated virus was delivered in the central or lateral region of the caudate putamen to ectopically co-express tyrosine hydroxylase and the GTP-cyclohydrolase (required by striatal cells to make tetrahydrobiopterin, an essential co-factor for tyrosine hydroxylase) (Szczypka et al., 2001), or when a retrograde canine adenovirus expressing the tyrosine hydroxylase was injected in the dorsal striatum (Sotak et al., 2005). Furthermore, a retrograde CAV2-Cre viral strategy could rescue feeding in tyrosine hydroxylase deficient mice by simply restoring the tyrosine hydroxylase gene selectively in neurons that project to the caudate putamen (Hnasko et al., 2006). These data converge to show that dopamine in the dorsal striatum may be critical to the aphagia associated with dopamine loss, and could partly explain the food-intake deficit that can be observed after bilateral SNc lesion. However, a 6-OHDA lesion that targets dopamine terminals only in the dorsolateral striatum is not sufficient per se to significantly alter weight gain, food and kcal intake, and preference for a specific food type. While this lack of impact was observed overall, some effect on food preference (increased fat intake) was however present in an animal whose lesion was extended to the ventrolateral part of the striatal complex.

Previous studies have shown that activation of VTA dopamine neurons projecting to the NAc is reinforcing (Tsai et al., 2009; Witten et al., 2011) and favors the frequency of feeding with smaller meal size, without affecting total food intake (Boekhoudt et al., 2017). When a D1 dopamine receptor agonist is given peripherally, it dose dependently affects palatable food consumption (MartinIverson and Dourish, 1988; Cooper et al., 1992). In this regard, the D1-expressing medium spiny neurons of the mNAC appears to be particularly sensitive to palatable food (Durst et al., 2019). Using recording and selective optogenetic manipulation of these neurons in the NAc shell, it has been shown that these neurons projecting to the lateral hypothalamus provide a rapid control over feeding and particularly feeding duration (O'Connor et al., 2015). Despite this well established and important control of fine aspects of feeding, we show that the more global overnight food intake and food choice were not altered by mNAc dopamine loss.

After high fat consumption, several studies have shown alterations in dopamine receptors, in dopamine transporter and in their mRNA levels in the nucleus accumbens (Huang et al., 2005, 2006; South and Huang, 2008; Sharma and Fulton, 2013; Adams et al., 2015; Hryhorczuk et al., 2016) and in the striatum (Alsio et al., 2010; Johnson and Kenny, 2010; Tellez et al., 2013). While fat intake can alter the dopamine system, less is reciprocally known on the role of the dopamine system in fat intake or preference. The binge consumption of sweetened high fat liquid in long Evans rats has for example been shown to be independent from NAc dopamine signaling (Lardeux et al., 2015), but this study was entirely carried out either in the core or medial NAc and did not address the potential influence of the INAc.

Previously, it has been shown that bilateral 6-OHDA lesions of dopamine terminals in the NAc can enhance food intake during 30-min sessions (Koob et al., 1978). In the present study, we found that more specific bilateral lesions of the INAc (but not of the mNAc) increased the daily total kcal intake, which was mainly driven by an increased intake of fat. This anatomical specificity within the NAc may be related to differences in connectivity within subregions of this nucleus. Indeed, the INAc and the $m N A c$ receive different dopamine innervation from the VTA, the INAc receiving dopamine inputs from the lateral region of the VTA and projecting back in turn to GABAergic neurons of the lateral VTA causing disinhibition, while mNAc receives dopamine inputs from the medial region of the VTA and sends back GABAergic projection to both the medial and lateral VTA dopamine neurons thus causing inhibition (Yang et al., 2018). This organization may for example contribute to the information flow related to the ascending spiral moving from the ventral to the dorsal striatum (Haber et al., 2000). Furthermore, the VTA dopamine neurons projecting to the INAc may receive afferents primarily from anterior cortical regions, including the prefrontal cortex, while the VTA dopamine neurons projecting to the mNAc may receive notable inputs from the dorsal raphe nucleus (Beier et al., 2015).

While we compared the respective impact of 6-OHDA lesions of the dorsolateral striatum, mNAc and INAc, it is to be noted that a subregion may be missing in this comparison: the dorsomedial part of the striatum. Indeed, this part of the striatum was also affected in animals with extended midbrain lesions. The dorsal striatum in rodents can be divided into its dorsomedial and dorsolateral regions, which would be somewhat analogous to the caudate and putamen nuclei in higher species with a prominent internal capsule (Haber, 2016). Clinically, a decreased activation of the caudate nucleus in response to the consumption of energy-dense food has been reported in obese relative to lean adolescent girls (Stice et al., 2008). In rats, an increase in enkephalin release was observed in the dorsomedial striatum after consumption of a palatable (chocolate) food (DiFeliceantonio et al., 2012); and the excitotoxic lesion of the dorsomedial striatum was shown to lower high-fat diet consumption, which was followed by increased chow consumption (Cole et al., 2017). Together, these data are supportive of a role of the dorsomedial striatum in food reward and food choice processing, but the impact of the excitotoxic lesion of this subregion on fat intake was opposite from what we observed after midbrain or INAc dopaminergic lesions.

It was somewhat surprising to observe that dopamine loss did not affect the sucrose consumption in the fcHFHS paradigm. Indeed, anhedonic response towards sucrose 
solution has been clearly reported with manipulation of dopamine systems or loss of dopamine neurons (DerAvakian and Markou, 2012; Santiago et al., 2014; Zhang et al., 2016; Kaminska et al., 2017; Faivre et al., 2020). However, dopamine deficient mice have higher rate of licking, bout size and duration with fewer total licks, without change in preference for sucrose (Cannon and Palmiter, 2003). Importantly, most of the anhedoniarelated studies are carried with low to mild concentrations of sucrose solution (0.5-5\%), while with higher concentrations of sucrose there can be a ceiling effect in the amount of sucrose taken daily (Wallace et al., 2008). It suggests that anhedonia-related studies are mostly highlighting dose-related shifts in sucrose preference rather than total loss of interest. In our study, we used the fcHFHS paradigm that relies on a high concentration of sucrose, which may mask dopamine-related modulation of the preference for sucrose (usually detected at thresholds doses) and explains why we did not observe any differences for overall sucrose consumption between 6-OHDA-lesioned and control animals.

With most NAc functional studies focusing on the mNAc, the importance of the INAc has been mostly neglected. The present study provides behavioral evidence that dopamine in the INAc is influential for food-type preference in food intake. Our results more specifically indicate that reducing the dopamine tone in this region was sufficient to favor fat intake in male rats. These findings provide a new insight into how dopamine influences food intake and food preference, opening the path for further research on INAc regulation of fat intake in normal and pathological states.

Funding

The present study was supported by the Centre National de la Recherche Scientifique (CNRS UPR3212), the University of Strasbourg, the University of Amsterdam, the Agence Nationale de la Recherche [ANR-15-CE37-0005-02; Euridol ANR-17-EURE-0022], the NeuroTime Erasmus Mundus Joint Doctorate, and by a NARSAD distinguish investigator grant from the Brain and Behavior Research Foundation [24220].

\section{DECLARATION OF COMPETING INTEREST}

The authors declare that they have no known competing financial interests or personal relationships that could have appeared to influence the work reported in this paper.

\section{ACKNOWLEDGEMENTS}

We thank the core facility Chronobiotron UMS3415 (Strasbourg, France) for animal care, and the UPS3156 in vitro imaging core facility (Strasbourg, France) for NanoZoomer scanning.

\section{REFERENCES}

Adams WK, Sussman JL, Kaur S, D'Souza AM, Kieffer TJ, Winstanley CA (2015) Long-term, calorie-restricted intake of a high-fat diet in rats reduces impulse control and ventral striatal D2 receptor signalling - two markers of addiction vulnerability. Eur $\mathrm{J}$ Neurosci 42:3095-3104. https://doi.org/10.1111/ejn.13117.

Ådén E, Carlsson M, Poortvliet E, Stenlund H, Linder J, Edström M, Forsgren L, Håglin L (2011) Dietary intake and olfactory function in patients with newly diagnosed Parkinson's disease: a casecontrol study. Nutr Neurosci 14:25-31. https://doi.org/10.1179/ $174313211 \times 12966635733312$.

Aiello M, Eleopra R, Rumiati RI (2015) Body weight and food intake in Parkinson's disease. A review of the association to non-motor symptoms. Appetite 84:204-211. https://doi.org/10.1016/j. appet.2014.10.011.

Alsio J, Olszewski PK, Norback AH, Gunnarsson ZE, Levine AS, Pickering C, Schioth HB (2010) Dopamine D1 receptor gene expression decreases in the nucleus accumbens upon long-term exposure to palatable food and differs depending on diet-induced obesity phenotype in rats. Neuroscience 171:779-787. https://doi. org/10.1016/j.neuroscience.2010.09.046.

Baker RW, Osman J, Bodnar RJ (2001) Differential actions of dopamine receptor antagonism in rats upon food intake elicited by either mercaptoacetate or exposure to a palatable high-fat diet. Pharmacol Biochem Behav 69:201-208. https://doi.org/10.1016/ s0091-3057(01)00528-7.

Beier KT, Steinberg EE, DeLoach KE, Xie S, Miyamichi K, Schwarz L, Gao XJ, Kremer EJ, et al. (2015) Circuit architecture of VTA dopamine neurons revealed by systematic input-output mapping. Cell 162:622-634. https://doi.org/10.1016/i.cell.2015.07.015.

Berke JD (2018) What does dopamine mean?. Nat Neurosci 21:787-793. https://doi.org/10.1038/s41593-018-0152-y.

Bezard E, Przedborski S (2011) A tale on animal models of Parkinson's disease. Mov Disord 26:993-1002. https://doi.org/ 10.1002/mds.23696.

Bieri G, Brahic M, Bousset L, Couthouis J, Kramer NJ, Ma R, Nakayama L, Monbureau M, et al. (2019) LRRK2 modifies alphasyn pathology and spread in mouse models and human neurons. Acta Neuropathol 137:961-980. https://doi.org/10.1007/s00401019-01995-0.

Boekhoudt L, Roelofs TJM, de Jong JW, de Leeuw AE, Luijendijk MCM, Wolterink-Donselaar IG, van der Plasse G, Adan RAH (2017), Does activation of midbrain dopamine neurons promote or reduce feeding? Int J Obes 41:1131-1140. 10.1038/ijo.2017.74

Cannon CM, Palmiter RD (2003) Reward without dopamine. J Neurosci 23:10827-10831. https://doi.org/10.1523/ JNEUROSCI.23-34-10827.2003.

Carr KD (2020) Homeostatic regulation of reward via synaptic insertion of calcium-permeable AMPA receptors in nucleus accumbens. Physiol Behav 219. https://doi.org/10.1016/ j.physbeh.2020.112850.

Castro DC, Bruchas MR (2019) A motivational and neuropeptidergic hub: anatomical and functional diversity within the nucleus accumbens shell. Neuron 102:529-552. https://doi.org/10.1016/ j.neuron.2019.03.003.

Clifton PG, Rusk IN, Cooper SJ (1991) Effects of dopamine $D_{1}$ and dopamine $D_{2}$ antagonists on the free feeding and drinking patterns of rats. Behav Neurosci 105:272-281. https://doi.org/ 10.1037/0735-7044.105.2.272.

Cole S, Stone AD, Petrovich GD (2017) The dorsomedial striatum mediates Pavlovian appetitive conditioning and food consumption. Behav Neurosci 131:447-453. https://doi.org/ 10.1037/bne0000216.

Cooper SJ, Francis J, Al-Naser H, Barber D (1992) Evidence for dopamine D-1 receptor-mediated facilitatory and inhibitory effects on feeding behaviour in rats. J Psychopharmacol 6:27-33. https:// doi.org/10.1177/026988119200600108.

Cox J, Witten IB (2019) Striatal circuits for reward learning and decision-making. Nat Rev Neurosci 20:482-494. https://doi.org/ 10.1038/s41583-019-0189-2.

Cuvelier E, Mequinion M, Leghay C, Sibran W, Stievenard A, Sarchione A, Bonte MA, Vanbesien-Mailliot C, et al. (2018) Overexpression of wild-type human alpha-synuclein causes metabolism abnormalities in Thy1-aSYN transgenic mice. Front Mol Neurosci 11:321. https://doi.org/10.3389/fnmol.2018.00321. 
da Silva JA, Tecuapetla F, Paixao V, Costa RM (2018) Dopamine neuron activity before action initiation gates and invigorates future movements. Nature 554:244-248. https://doi.org/ 10.1038/nature25457.

Dang LC, Samanez-Larkin GR, Castrellon JJ, Perkins SF, Cowan $\mathrm{RL}$, Zald DH (2016) Associations between dopamine D2 receptor availability and BMI depend on age. Neuroimage 138:176-183. https://doi.org/10.1016/j.neuroimage.2016.05.044.

de Araujo IE, Oliveira-Maia AJ, Sotnikova TD, Gainetdinov RR, Caron MG, Nicolelis MA, Simon SA (2008), Food reward in the absence of taste receptor signaling. Neuron 57:930-941. 10.1016/ j.neuron.2008.01.032.

de Weijer BA, van de Giessen E, van Amelsvoort TA, Boot E, Braak B, Janssen IM, van de Laar A, Fliers E, et al. (2011) Lower striatal dopamine D2/3 receptor availability in obese compared with nonobese subjects. EJNMMI Res 1:37. https://doi.org/10.1186/2191219X-1-37.

Der-Avakian A, Markou A (2012) The neurobiology of anhedonia and other reward-related deficits. Trends Neurosci 35:68-77. https:// doi.org/10.1016/i.tins.2011.11.005.

DiFeliceantonio AG, Coppin G, Rigoux L, Edwin Thanarajah S, Dagher A, Tittgemeyer M, Small DM (2018) Supra-additive effects of combining fat and carbohydrate on food reward. Cell Metab 28 (33-44). https://doi.org/10.1016/j.cmet.2018.05.018.

DiFeliceantonio AG, Mabrouk OS, Kennedy RT, Berridge KC (2012) Enkephalin surges in dorsal neostriatum as a signal to eat. Curr Biol 22:1918-1924. https://doi.org/10.1016/i.cub.2012.08.014.

Durst M, Konczol K, Balazsa T, Eyre MD, Toth ZE (2019) Rewardrepresenting D1-type neurons in the medial shell of the accumbens nucleus regulate palatable food intake. Int $\mathrm{J}$ Obes 43:917-927. https://doi.org/10.1038/s41366-018-0133-y.

Eisenstein SA, Antenor-Dorsey JA, Gredysa DM, Koller JM, Bihun EC, Ranck SA, Arbeláez AM, Klein S, et al. (2013) A comparison of D2 receptor specific binding in obese and normal-weight individuals using PET with $(\mathrm{N}-[(11) \mathrm{C}]$ methyl)benperidol. Synapse 67:748-756. https://doi.org/10.1002/syn.21680.

Faivre F, Joshi A, Bezard E, Barrot M (2019) The hidden side of Parkinson's disease: Studying pain, anxiety and depression in animal models. Neurosci Biobehav Rev 96:335-352. https://doi. org/10.1016/j.neubiorev.2018.10.004.

Faivre F, Sanchez-Catalan MJ, Dovero S, Bido S, Joshi A, Bezard E, Barrot M (2020) Ablation of the tail of the ventral tegmental area compensates symptoms in an experimental model of Parkinson's disease. Neurobiol Dis 139. https://doi.org/10.1016/j. nbd.2020.104818.

Fernandes AB, Alves da Silva J, Almeida J, Cui G, Gerfen CR, Costa RM, Oliveira-Maia AJ (2020) Postingestive modulation of food seeking depends on vagus-mediated dopamine neuron activity. Neuron 106:1-11. https://doi.org/10.1016/i.neuron.2020.03.009.

Ferreira JG, Tellez LA, Ren X, Yeckel CW, de Araujo IE (2012) Regulation of fat intake in the absence of flavour signalling. $J$ Physiol 590:953-972. https://doi.org/10.1113/ jphysiol.2011.218289.

Fletcher PC, Kenny PJ (2018) Food addiction: a valid concept?. Neuropsychopharmacology 43:2506-2513. https://doi.org/ 10.1038/s41386-018-0203-9.

Fritz BM, Munoz B, Yin F, Bauchle C, Atwood BK (2018) A high-fat, high-sugar 'western' diet alters dorsal striatal glutamate, opioid, and dopamine transmission in mice. Neuroscience 372:1-15. https://doi.org/10.1016/j.neuroscience.2017.12.036.

Gaiser EC, Gallezot J-D, Worhunsky PD, Jastreboff AM, Pittman B, Kantrovitz L, Angarita GA, Cosgrove KP, et al. (2016) Elevated dopamine $D(2 / 3)$ receptor availability in obese individuals: a PET imaging study with [(11)C](+)PHNO. Neuropsychopharmacology 41:3042-3050. https://doi.org/10.1038/npp.2016.115.

Gerfen CR, Bolam JP (2016) Chapter 1 - The Neuroanatomical Organization of the Basal Ganglia. Elsevier. 10.1016/B978-0-12802206-1.00001-5.

Giasson BI, Duda JE, Quinn SM, Zhang B, Trojanowski JQ, Lee VM (2002) Neuronal alpha-synucleinopathy with severe movement disorder in mice expressing A53T human alpha-synuclein.
Neuron 34:521-533. https://doi.org/10.1016/s0896-6273(02) 00682-7.

Gilbert DB, Cooper SJ (1985) Analysis of dopamine D1 and D2 receptor involvement in d- and l-amphetamine-induced anorexia in rats. Brain Res Bull 15:385-389. https://doi.org/10.1016/03619230(85)90006-1.

Gispert S, Ricciardi F, Kurz A, Azizov M, Hoepken HH, Becker D, Voos W, Leuner K, et al. (2009) Parkinson phenotype in aged PINK1-deficient mice is accompanied by progressive mitochondrial dysfunction in absence of neurodegeneration. PLoS One 4. https://doi.org/10.1371/journal.pone.0005777.

Haber SN (2016), Corticostriatal circuitry. Dialogues Clin Neurosci 18:7-21. 10.31887/DCNS.2016.18.1/shaber.

Haber SN, Fudge JL, McFarland NR (2000) Striatonigrostriatal pathways in primates form an ascending spiral from the shell to the dorsolateral striatum. J Neurosci 20:2369-2382. https://doi. org/10.1523/JNEUROSCI.20-06-02369.2000.

Hajnal A, Smith GP, Norgren R (2004) Oral sucrose stimulation increases accumbens dopamine in the rat. Am J Physiol Regul Integr Comp Physiol 286:R31-37. https://doi.org/10.1152/ aipregu.00282.2003.

Hamid AA, Pettibone JR, Mabrouk OS, Hetrick VL, Schmidt R, Vander Weele CM, Kennedy RT, Aragona BJ, et al. (2016), Mesolimbic dopamine signals the value of work. Nat Neurosci 19:117-126. 10.1038/nn.4173.

Han W, Tellez LA, Perkins MH, Perez IO, Qu T, Ferreira J, Ferreira TL, Quinn D, et al. (2018) A neural circuit for gut-induced reward 665-678 e623. Cell 175. https://doi.org/10.1016/ j.cell.2018.08.049.

Hellenbrand W, Seidler A, Boeing H, Robra BP, Vieregge P, Nischan P, Joerg J, Oertel WH, et al. (1996) Diet and Parkinson's disease. I: A possible role for the past intake of specific foods and food groups. Results from a self-administered food-frequency questionnaire in a case-control study. Neurology 47:636-643. https://doi.org/10.1212/wnl.47.3.636.

Hernandez L, Hoebel BG (1988) Feeding and hypothalamic stimulation increase dopamine turnover in the accumbens. Physiol Behav 44:599-606. https://doi.org/10.1016/0031-9384 (88)90324-1.

Hnasko TS, Perez FA, Scouras AD, Stoll EA, Gale SD, Luquet S, Phillips PE, Kremer EJ, et al. (2006) Cre recombinase-mediated restoration of nigrostriatal dopamine in dopamine-deficient mice reverses hypophagia and bradykinesia. Proc Natl Acad Sci U S A 103:8858-8863. https://doi.org/10.1073/pnas.0603081103.

Hoebel BG (1985) Brain neurotransmitters in food and drug reward. Am J Clin Nutr 42:1133-1150. https://doi.org/10.1093/ajcn/ 42.5.1133.

Howe MW, Dombeck DA (2016) Rapid signalling in distinct dopaminergic axons during locomotion and reward. Nature 535:505-510. https://doi.org/10.1038/nature18942.

Hryhorczuk C, Florea M, Rodaros D, Poirier I, Daneault C, Des Rosiers C, Arvanitogiannis A, Alquier T, et al. (2016) Dampened mesolimbic dopamine function and signaling by saturated but not monounsaturated dietary lipids. Neuropsychopharmacology 41:811-821. https://doi.org/10.1038/npp.2015.207.

$\mathrm{Hu} \mathrm{H}$ (2016) Reward and aversion. Annu Rev Neurosci 39:297-324. https://doi.org/10.1146/annurev-neuro-070815-014106.

Huang XF, Yu Y, Zavitsanou K, Han M, Storlien L (2005) Differential expression of dopamine D2 and D4 receptor and tyrosine hydroxylase mRNA in mice prone, or resistant, to chronic highfat diet-induced obesity. Mol Brain Res 135:150-161. https://doi. org/10.1016/j.molbrainres.2004.12.013.

Huang XF, Zavitsanou K, Huang X, Yu Y, Wang H, Chen F, Lawrence AJ, Deng C (2006) Dopamine transporter and D2 receptor binding densities in mice prone or resistant to chronic high fat diet-induced obesity. Behav Brain Res 175:415-419. https://doi.org/10.1016/i. bbr.2006.08.034.

llango A, Kesner AJ, Keller KL, Stuber GD, Bonci A, Ikemoto S (2014) Similar roles of substantia nigra and ventral tegmental dopamine neurons in reward and aversion. J Neurosci 34:817-822. https:// doi.org/10.1523/JNEUROSCI.1703-13.2014. 
Johnson PM, Kenny PJ (2010) Dopamine D2 receptors in addictionlike reward dysfunction and compulsive eating in obese rats. Nat Neurosci 13:635-641. https://doi.org/10.1038/nn.2519.

Kaminska K, Lenda T, Konieczny J, Czarnecka A, Lorenc-Koci E (2017) Depressive-like neurochemical and behavioral markers of Parkinson's disease after 6-OHDA administered unilaterally to the rat medial forebrain bundle. Pharmacol Rep 69:985-994. https:// doi.org/10.1016/j.pharep.2017.05.016.

Kistner A, Lhommee E, Krack P (2014) Mechanisms of body weight fluctuations in Parkinson's disease. Front Neurol 5:84. https://doi. org/10.3389/fneur.2014.00084.

Koob GF, Riley SJ, Smith SC, Robbins TW (1978) Effects of 6hydroxydopamine lesions of the nucleus accumbens septi and olfactory tubercle on feeding, locomotor activity, and amphetamine anorexia in the rat. J Comp Physiol Psychol 92:917-927. https://doi.org/10.1037/h0077542.

la Fleur SE, Luijendijk MC, van der Zwaal EM, Brans MA, Adan RA (2014) The snacking rat as model of human obesity: effects of a free-choice high-fat high-sugar diet on meal patterns. Int $\mathrm{J}$ Obes 38:643-649. https://doi.org/10.1038/ijo.2013.159.

la Fleur SE, Luijendijk MC, van Rozen AJ, Kalsbeek A, Adan RA (2011) A free-choice high-fat high-sugar diet induces glucose intolerance and insulin unresponsiveness to a glucose load not explained by obesity. Int J Obes 35:595-604. https://doi.org/ 10.1038/ijo.2010.164.

la Fleur SE, van Rozen AJ, Luijendijk MC, Groeneweg F, Adan RA (2010) A free-choice high-fat high-sugar diet induces changes in arcuate neuropeptide expression that support hyperphagia. Int $\mathrm{J}$ Obes 34:537-546. https://doi.org/10.1038/ijo.2009.257.

Lammel S, Lim BK, Ran C, Huang KW, Betley MJ, Tye KM, Deisseroth K, Malenka RC (2012) Input-specific control of reward and aversion in the ventral tegmental area. Nature 491:212-217. https://doi.org/10.1038/nature11527.

Lardeux S, Kim JJ, Nicola SM (2015) Intermittent-access binge consumption of sweet high-fat liquid does not require opioid or dopamine receptors in the nucleus accumbens. Behav Brain Res 292:194-208. https://doi.org/10.1016/j.bbr.2015.06.015.

Lee K, Claar LD, Hachisuka A, Bakhurin KI, Nguyen J, Trott JM, Gill $\mathrm{JL}$, Masmanidis SC (2020) Temporally restricted dopaminergic control of reward-conditioned movements. Nat Neurosci 23:209-216. https://doi.org/10.1038/s41593-019-0567-0.

Li X, Redus L, Chen C, Martinez PA, Strong R, Li S, O'Connor JC (2013) Cognitive dysfunction precedes the onset of motor symptoms in the MitoPark mouse model of Parkinson's disease. PLoS One 8. https://doi.org/10.1371/journal.pone.0071341.

Liang NC, Hajnal A, Norgren R (2006) Sham feeding corn oil increases accumbens dopamine in the rat. Am J Physiol Regul Integr Comp Physiol 291:R1236-1239. https://doi.org/10.1152/ ajpregu.00226.2006.

London TD, Licholai JA, Szczot I, Ali MA, LeBlanc KH, Fobbs WC, Kravitz AV (2018) Coordinated ramping of dorsal striatal pathways preceding food approach and consumption. J Neurosci 38:3547-3558. https://doi.org/10.1523/ JNEUROSCI.2693-17.2018.

Lorefält B, Granérus A-K, Unosson M (2006) Avoidance of solid food in weight losing older patients with Parkinson's disease. J Clin Nurs 15:1404-1412. https://doi.org/10.1111/i.13652702.2005.01454.x.

Luo YJ, Li YD, Wang L, Yang SR, Yuan XS, Wang J, Cherasse Y, Lazarus M, et al. (2018) Nucleus accumbens controls wakefulness by a subpopulation of neurons expressing dopamine D1 receptors. Nat Commun 9:1576. https://doi.org/ 10.1038/s41467-018-03889-3.

Ma K, Xiong N, Shen Y, Han C, Liu L, Zhang G, Wang L, Guo S, et al. (2018) Weight loss and malnutrition in patients with parkinson's disease: current knowledge and future prospects. Front Aging Neurosci 10:1. https://doi.org/10.3389/fnagi.2018.00001.

Martin-Iverson MT, Dourish CT (1988) Role of dopamine D-1 and D-2 receptor subtypes in mediating dopamine agonist effects on food consumption in rats. Psychopharmacology 96:370-374. https:/ doi.org/10.1007/BF00216064.
Meyers C, Amick MA, Friedman JH (2010) Ice cream preference in Parkinson's disease. Med Health R I 93:91-92.

Mogenson GJ, Jones DL, Yim CY (1980) From motivation to action: functional interface between the limbic system and the motor system. Prog Neurobiol 14:69-97. https://doi.org/10.1016/03010082(80)90018-0.

Morales M, Margolis EB (2017) Ventral tegmental area: cellular heterogeneity, connectivity and behaviour. Nat Rev Neurosci 18:73-85. https://doi.org/10.1038/nrn.2016.165.

Munoz-Manchado AB, Villadiego J, Romo-Madero S, Suarez-Luna N, Bermejo-Navas A, Rodriguez-Gomez JA, Garrido-Gil P, Labandeira-Garcia JL, et al. (2016), Chronic and progressive Parkinson's disease MPTP model in adult and aged mice. J Neurochem 136:373-387. 10.1111/jnc.13409.

O'Connor EC, Kremer Y, Lefort S, Harada M, Pascoli V, Rohner C, Luscher C (2015), Accumbal D1R Neurons Projecting to Lateral Hypothalamus Authorize Feeding. Neuron 88:553-564. 10.1016/j. neuron.2015.09.038.

Palmiter RD (2008) Dopamine signaling in the dorsal striatum is essential for motivated behaviors: lessons from dopaminedeficient mice. Ann N Y Acad Sci 1129:35-46. https://doi.org/ 10.1196/annals.1417.003.

Park Y-S, Sammartino F, Young NA, Corrigan J, Krishna V, Rezai AR (2019) Anatomic review of the ventral capsule/ventral striatum and the nucleus accumbens to guide target selection for deep brain stimulation for obsessive-compulsive disorder. World Neurosurg 126:1-10. https://doi.org/10.1016/i.wneu.2019.01.254.

Paxinos G, Watson C (2013) The Rat Brain in Stereotaxic Coordinates. Academic Press.

Porras G, Li Q, Bezard E (2012) Modeling Parkinson's disease in primates: the MPTP model. Cold Spring Harb Perspect Med 2. https://doi.org/10.1101/cshperspect.a009308.

Rada P, Avena NM, Barson JR, Hoebel BG, Leibowitz SF (2012) A high-fat meal, or intraperitoneal administration of a fat emulsion, increases extracellular dopamine in the nucleus accumbens. Brain Sci 2:242-253. https://doi.org/10.3390/brainsci2020242.

Randall PA, Lee CA, Podurgiel SJ, Hart E, Yohn SE, Jones M, Rowland M, Lopez-Cruz L, et al. (2014) Bupropion increases selection of high effort activity in rats tested on a progressive ratio/chow feeding choice procedure: implications for treatment of effort-related motivational symptoms. Int J Neuropsychopharmacol 18(pyu017). https://doi.org/10.1093/iinp/ pyu017.

Rolls ET, Rolls BJ, Kelly PH, Shaw SG, Wood RJ, Dale R (1974) The relative attenuation of self-stimulation, eating and drinking produced by dopamine-receptor blockade. Psychopharmacologia 38:219-230. https://doi.org/10.1007/ BF00421374.

Santiago RM, Barbiero J, Gradowski RW, Bochen S, Lima MM, Da Cunha C, Andreatini R, Vital MA (2014) Induction of depressivelike behavior by intranigral 6-OHDA is directly correlated with deficits in striatal dopamine and hippocampal serotonin. Behav Brain Res 259:70-77. https://doi.org/10.1016/j.bbr.2013.10.035.

Sharma S, Fulton S (2013) Diet-induced obesity promotes depressive-like behaviour that is associated with neural adaptations in brain reward circuitry. Int $\mathrm{J}$ Obes 37:382-389. https://doi.org/10.1038/iijo.2012.48.

Slomp M, Belegri E, Blancas-Velazquez AS, Diepenbroek C, Eggels L, Gumbs MCR, Joshi A, Koekkoek LL, et al. (2019) Stressing the importance of choice: Validity of a preclinical free-choice highcaloric diet paradigm to model behavioural, physiological and molecular adaptations during human diet-induced obesity and metabolic dysfunction. J Neuroendocrinol 31. https://doi.org/ 10.1111/ine. 12718 .

Sotak BN, Hnasko TS, Robinson S, Kremer EJ, Palmiter RD (2005) Dysregulation of dopamine signaling in the dorsal striatum inhibits feeding. Brain Res 1061:88-96. https://doi.org/10.1016/j. brainres.2005.08.053.

South T, Huang XF (2008) High-fat diet exposure increases dopamine D2 receptor and decreases dopamine transporter receptor binding density in the nucleus accumbens and caudate 
putamen of mice. Neurochem Res 33:598-605. https://doi.org/ 10.1007/s11064-007-9483-x.

Stice E, Spoor S, Bohon C, Veldhuizen MG, Small DM (2008) Relation of reward from food intake and anticipated food intake to obesity: a functional magnetic resonance imaging study. J Abnorm Psychol 117:924-935. https://doi.org/10.1037/a0013600.

Sundstrom E, Fredriksson A, Archer T (1990) Chronic neurochemical and behavioral changes in MPTP-lesioned C57BL/6 mice: a model for Parkinson's disease. Brain Res 528:181-188. https:// doi.org/10.1016/0006-8993(90)91656-2.

Szczypka MS, Kwok K, Brot MD, Marck BT, Matsumoto AM, Donahue BA, Palmiter RD (2001) Dopamine production in the caudate putamen restores feeding in dopamine-deficient mice. Neuron 30:819-828. https://doi.org/10.1016/s0896-6273(01) 00319-1.

Tellez LA, Medina S, Han W, Ferreira JG, Licona-Limon P, Ren X, Lam TT, Schwartz GJ, et al. (2013) A gut lipid messenger links excess dietary fat to dopamine deficiency. Science 341:800-802. https://doi.org/10.1126/science.1239275.

Terry P, Katz JL (1992) Differential antagonism of the effects of dopamine D1-receptor agonists on feeding behavior in the rat. Psychopharmacology 109:403-409. https://doi.org/10.1007/ BF02247715.

Tsai HC, Zhang F, Adamantidis A, Stuber GD, Bonci A, de Lecea L, Deisseroth K (2009) Phasic firing in dopaminergic neurons is sufficient for behavioral conditioning. Science 324:1080-1084. https://doi.org/10.1126/science.1168878.

Ungerstedt U (1968) 6-Hydroxy-dopamine induced degeneration of central monoamine neurons. Eur J Pharmacol 5:107-110. https:// doi.org/10.1016/0014-2999(68)90164-7.

Ungerstedt U (1971) Adipsia and aphagia after 6-hydroxydopamine induced degeneration of the nigro-striatal dopamine system. Acta Physiol Scand Suppl 367:95-122. https://doi.org/10.1111/j.1365201x.1971.tb11001.x.

van de Giessen E, de Bruin K, la Fleur SE, van den Brink W, Booij J (2012) Triple monoamine inhibitor tesofensine decreases food intake, body weight, and striatal dopamine D2/D3 receptor availability in diet-induced obese rats. Eur Neuropsychopharmacol 22:290-299. https://doi.org/10.1016/j. euroneuro.2011.07.015.

van de Giessen E, la Fleur SE, Eggels L, de Bruin K, van den Brink W, Booij J (2013) High fat/carbohydrate ratio but not total energy intake induces lower striatal dopamine D2/3 receptor availability in diet-induced obesity. Int J Obes 37:754-757. https://doi.org/ 10.1038/ijo.2012.128.

Volkow ND, Wise RA, Baler R (2017) The dopamine motive system: implications for drug and food addiction. Nat Rev Neurosci 18:741-752. https://doi.org/10.1038/nrn.2017.130.

Wallace DL, Vialou V, Rios L, Carle-Florence TL, Chakravarty S, Kumar A, Graham DL, Green TA, et al. (2008) The influence of
DeltaFosB in the nucleus accumbens on natural reward-related behavior. J Neurosci 28:10272-10277. https://doi.org/10.1523/ JNEUROSCl.1531-08.2008.

Wang GJ, Volkow ND, Logan J, Pappas NR, Wong CT, Zhu W, Netusil N, Fowler JS (2001) Brain dopamine and obesity. Lancet 357:354-357. https://doi.org/10.1016/s0140-6736(00)03643-6.

Witten IB, Steinberg EE, Lee SY, Davidson TJ, Zalocusky KA, Brodsky M, Yizhar O, Cho SL, et al. (2011) Recombinase-driver rat lines: tools, techniques, and optogenetic application to dopamine-mediated reinforcement. Neuron 72:721-733. https:// doi.org/10.1016/i.neuron.2011.10.028.

Wolz M, Kaminsky A, Löhle M, Koch R, Storch A, Reichmann H (2009) Chocolate consumption is increased in Parkinson's disease. J Neurol 256:488-492. https://doi.org/10.1007/s00415009-0118-9.

Yang H, de Jong JW, Tak Y, Peck J, Bateup HS, Lammel S (2018) Nucleus accumbens subnuclei regulate motivated behavior via direct inhibition and disinhibition of VTA dopamine subpopulations 434-449 e434. Neuron 97. https://doi.org/10.1016/i. neuron.2017.12.022.

Záborszky L, Alheid GF, Beinfeld MC, Eiden LE, Heimer L, Palkovits M (1985) Cholecystokinin innervation of the ventral striatum: a morphological and radioimmunological study. Neuroscience 14:427-453. https://doi.org/10.1016/0306-4522(85)90302-1.

Zahm DS (1999) Functional-anatomical implications of the nucleus accumbens core and shell subterritories. Ann N Y Acad Sci 877:113-128. https://doi.org/10.1111/i.1749-6632.1999.tb09264. x.

Zhang QS, Heng Y, Mou Z, Huang JY, Yuan YH, Chen NH (2017) Reassessment of subacute MPTP-treated mice as animal model of Parkinson's disease. Acta Pharmacol Sin 38:1317-1328. https://doi.org/10.1038/aps.2017.49.

Zhang YM, Zhang L, Wang Y, Sun YN, Guo Y, Du CX, Zhang J, Yao L, et al. (2016) Activation and blockade of prelimbic 5-HT6 receptors produce different effects on depressive-like behaviors in unilateral 6-hydroxydopamine-induced Parkinson's rats. Neuropharmacology 110:25-36. https://doi.org/10.1016/i. neuropharm.2016.07.014.

Zhou QY, Palmiter RD (1995) Dopamine-deficient mice are severely hypoactive, adipsic, and aphagic. Cell 83:1197-1209. https://doi. org/10.1016/0092-8674(95)90145-0.

Zimmerman CA, Knight ZA (2020) Layers of signals that regulate appetite. Curr Opin Neurobiol 64:79-88. https://doi.org/10.1016/ j.conb.2020.03.007.

\section{APPENDIX A. SUPPLEMENTARY DATA}

Supplementary data to this article can be found online at https://doi.org/10.1016/j. neuroscience.2021.05.022. 